\title{
Tools for Rating Evaluation of Human Resources as the Main Factor for Providing the Innovation Development of the Sea Ports
}

\author{
Liudmyla Nikolaieva* \\ Department of Marine Transportation \\ National University "Odessa Marine \\ Academy" \\ Odessa, Ukraine \\ https://orcid.org/0000-0002-5887-702X
}

\author{
Oleksandr Haichenia \\ Department of Marine Transportation \\ National University "Odessa Marine \\ Academy" \\ Odessa, Ukraine \\ https://orcid.org/0000-0002-7899-4418 \\ Victoriia Kozlova \\ Department of Accounting and Audit \\ Pryazovskyi state technical university \\ Mariupol, Ukraine \\ https://orcid.org/0000-0003-4444-3378
}

\author{
Taras Omelchenko \\ Department of Marine Transportation \\ National University "Odessa Marine \\ Academy" \\ Odessa, Ukraine \\ https://orcid.org/0000-0003-1130-2883
}

\begin{abstract}
It is substantiated that the revitalization of innovative activity of seaports can be caused by the corresponding development of human resources. Unlike the existing ones, it takes into account the need for changes in the provision of working conditions suitable for innovation activity, the practical use of which makes it possible to adapt the system of human resources management to the features of innovative development of seaports. The approach to the assessment of the state of management of human resources innovative activity is formed, which is based on the methodology of rating estimation according to the factors that determine the state of human resources, provide for the activation of innovative activity, characterize the economic efficiency, the practical implementation of which will allow justifying the management decisions in the sphere of human resources management and compare results with other enterprises in the industry. It is proposed to supplement the assessment with the graphical presentation of the results of the analysis in the form of constructing a profile of the situation in managing the innovation activity of human resources of the seaport. An approach is proposed to identify the areas of analysis of the state of the innovative activity management of seaports based on the use of sub-rating indicators, which will provide a basis for the development of recommendations and rapid response to improve the quality of management of human resources innovation activity. It is recommended to supplement the analysis by conducting clustering analysis method and by grouping enterprises to identify similar groups. Such a management tool gives the manager additional information about the possibility of determining the impact of similar external environmental factors on the enterprises of the same group and becomes the basis for making management decisions at different levels.
\end{abstract}

Keywords-innovative activity, development of the ports, rating estimation, human resources, innovative activity management

\section{INTRODUCTION}

In post-industrial society, knowledge materialized in goods and services forms an increasing part of newly created value. This process develops due to the growth of the scientific intensity of the manufactured products and the development of the market of intellectually innovative goods and services. According to expert evaluations, the world market of innovative goods and services today is growing five times faster than traditional markets [1], [2].

It is no coincidence that commercial ports have become the focus of the study. Globally, about $60 \%$ of international trade is served by marine transport, an integral part of which is the infrastructure of the port industry.

As Ukraine's own experience has shown, as well as the practice of foreign countries, ports are one of the main sources of economic growth of the country.

As Ukraine is at the crossroads of leading trade routes, the development of commercial ports can become a competitive advantage. But for this purpose it is necessary to deal with the modernization of the transport complex of the country, its innovative development.

As it is demonstrated by Japan, which is one of the most innovation-oriented countries in the world that for 43 years (1968-2009) held the second place in the scope of GDP, being behind only the United States, the intellectualization of technologies used has led to a sharp increase in labor productivity.

Certainly, innovative development of the enterprise is understood as a complex process of economic growth based on the implementation of innovations.

Therefore, an enterprise in its activities should seek to implement innovations in each of its functional units.

Today the concept of the port has been transformed. It no longer covers only its main function - to provide transshipment and delivery of goods [1], [2].

The modern port is regarded as an integrated system of complex activities, including production and logistics, aimed to strengthen transcontinental freight flows in the world trade.

That is, on the one hand, the ports are focused on maximizing the efficiency of cargo handling operations and, on the other hand, the necessary functions of the port are becoming more complex and diverse. 


\section{SUBSTANTIATION FOR THE USE OF A COMPREHENSIVE RATING ASSESSMENT OF HUMAN RESOURCES AT THE SEAPORTS}

Research into the concept of human resource innovation activity management, approaches to its implementation, determination of the range of factors that determine its status in the sea commercial ports give the basis for making relevant conclusions on the directions of improving the management. Such conclusions can be based on a comprehensive assessment of the current state and prospects of development of human resource innovative activity management. One of the forms of such a comprehensive assessment is a rating-based assessment methodology (ranking of indicators) which gives the opportunity to get a comprehensive picture of the situation in the research sphere at the relevant enterprise of the marine industry. Formation of a methodological approach to the procedure for assessing the state of management of human resources innovative activity is aimed primarily at identifying weaknesses in the chain "human resources - innovation activity - efficiency and competitiveness of the enterprise". Carrying out such an assessment will allow the head of the enterprise to obtain an integrated, complex assessment, having developed at his own enterprise, as well as to see the situation in the industry, to determine its competitors. Therefore, such an assessment, first of all, is required by the enterprise itself to make sound management decisions regarding its innovative development. In addition, this assessment attracts the attention of promising human resources that are focused on selfactualization and are looking for the enterprises that create the required conditions for their employees. Also, evaluation is needed for service consumers, as innovative development creates interesting and high-quality offer at the industry market. An interested party may also be regional and state authorities, potential investors, who also need to have an adequate background, up-to-date information on the state of the enterprise and its position at the market. As we can see, the enterprise itself (the sea commercial port) is the initiator and direct performer of the assessment of the state of management of human resources innovative activity. The purpose of this assessment is twofold: on the one hand, to see the real situation at the enterprise, the proper use of human resources, and on the other hand, to increase the attention of consumers, competitors, public authorities and investors.

Such an increase in attention can have a positive impact on the performance of the enterprise in case of positive evaluation results. Otherwise, the assessment may aggravate the situation and adversely affect the position of the company at the market. However, even at the risk of losing money as a result of reduced interest from the consumers, the state and investors, it is necessary to assess the state of management of human resources innovative activity because, otherwise, the enterprise may lose much more. So, in that case, it will have the stimulus to improve its results. Assessment of the state of human resource innovative activity management is, on the one hand, an internal tool that determines the direction of management efforts, on the other hand, a means of making sound decisions about the innovative development of the enterprise.

The methodology for assessing the state of human resource innovative activity management based on rating assessment is a somewhat new tool in this field.
Analysis of publications in the field of evaluation of human resources management systems, as well as establishing relationships between the performance indicators of enterprise innovative activity and performance indicators of human resources use, allows us to distinguish two basic concepts that underlie such assessments.

Accordingly, the first of these is the efficiency of human resources management, based on the unity of management and production, but the contribution of human resources management itself to the efficiency of production is not determined. The second concept emphasizes the determination of the contribution of human resource management to production efficiency. The second concept is the most complex, but it helps to get more sophisticated and detailed information, helps to see the contribution of individual elements of the control system. To use it we require the development of a special system of indicators that reflect the relationship between enterprise performance indicators and performance indicators of human resources.

Therefore, when assessing the state of management of human resources innovative activity it is necessary to conduct an assessment of human resources of the enterprise, since in the current conditions they are the main factor of innovative development of the enterprise, this is a very important aspect of the enterprise.

The process of innovative development of the enterprise is ensured by employees and they also act as interested parties in the conductiong of assessment.

Further, the evaluation should take into account the economic efficiency of the port and, in particular, the economic efficiency of the enterprise in determining the rating.

The human resource innovative activity management system is a natural mechanism that, above all, ensures economic efficiency.

Accordingly, the characteristics of a system of such management must be judged by the criterion of how much they contribute to improving the efficiency of the enterprise functioning. In addition, the specific use of human resources in modern conditions for enterprises aimed at innovative development involves the creation of conditions that, first, become a condition for self-actualization of a person in professional activity; secondly, it serves as a catalyst for the synergy of the goals of the enterprise and the instrumental (prosperous human existence) goals of the employee; thirdly, it becomes a factor for improving the efficiency of the enterprise. As stated above, there is an opportunity to improve the methodology for managing the innovative activity of human resources, primarily through the inclusion in the consideration of new groups of factors characteristic for modern ports.

\section{PROCEDURE FOR RATING ASSESSMENT OF THE STATUS OF HUMAN RESOURCES AT THE SEAPORTS}

The basis for forming a methodology for assessing the state of human resource innovative activity management through the use of ratings is a comprehensive approach. Within it, various characteristics of the research object are examined in order to get an idea of its composition, that is, its analysis. The final stage is the formation of a single, 
unified view on the object, taking into account all the selected aspects, i.e., the synthesis. In order to develop an alternative methodology, it is recommended to evaluate the factors that determine the state of human resource innovative activity management in order to determine the weight of each of them, provided that the total weight of the whole set of factors equals 100. Obviously, such a question as determining the weight coefficient of some factor may not have a fully reasoned decision, but for these purposes it is recommended that experts express their views on the impact of each of them. It is supposed that each of them can be assigned a rating value to provide an opportunity to get an idea of the level of management of human resources innovative activity at the enterprise. A 100-point scale is accepted for rating. Rating 0 is received by the ports in which the picture is negative by all selected factors, rating 100 - ports whose situation is optimal for all selected factors. The procedure of rating evaluation of the state of management of human resources innovative activity has a certain purpose, structure of directions and is carried out at several stages. At the first three stages, an expert assessment of the weight of the factors that determine the state of managing the innovation activity of human resources of the port is conducted. Experts are suggested evaluating:

- the specific share of the areas of assessment (human resources, conditions that ensure innovative activity of human resources and economic efficiency of the port) in the overall assessment of the state of innovative activity of human resources (stage 1);

- the specific share of blocks of factors within the given direction of assessment (stage 2);

- the specific share of a particular factor that is assigned to a ceratin block of this or that direction (stage 3).

The fourth stage of the assessment involves the expert assessment of the state of management of human resources innovative activity at the respective ports according to the determined factors and their weight coefficients.

At each stage there are 10 points available to the expert. At the same time at the first three stages it is necessary to distribute the given 10 points between the defined directions, blocks, factors. At the fourth stage - to evaluate (basing on the maximum score of each factor also of 10 points) the state of management of human resources innovative activity in a specific sea commercial port.

Summarizing the results of the assessment by factors becomes the basis for determining the integrated and a number of specific rating indicators, the value of which is used to determine the rating group of sea commercial ports.

Thus, the described procedure for rating of the state of management of human resources innovative activity supposes:

- first, the expert determination of the weight of each of the factors that characterize the state of human resources management, i.e., the significance of their impact on the final result,

- second, expert assessment of the intensity of manifestation of a complex of factors in a particular sea commercial port. However, the forming of a general procedure requires particular determination and detailing of its stages in order to ensure the possibility of calculations based on information of the actual intensity of manifestation of individual factors in the sea ports.

The basis for assessing the state of management of human resources innovative activity was made by 17 sea commercial ports of the Azov-Black Sea basin [3]-[13]

The experts were representatives of the top management of the branches of the state enterprise "Administration of the sea ports of Ukraine", heads of the ports, heads of the functional divisions and specialists of human resources departments. As it has already been mentioned, the experts faced a double task. It was, first of all, to determine the weight of the components of the system of management of human resources innovative activity, that is, to fill the general methodological base with specific numerical values, which will become the basis for calculations. Second, the task of the experts was to assess the actual intensity of the manifestation of individual factors in specific seaports, that is, a factorial assessment of the state of management of human resources innovative activity. It should be noted that determining the weight of any factor of a phenomenon is a very specific task. The lack of a general view on the problem of human resource innovative management and the qualitative nature of the interrelation of factors and the targeted function - the state of human resource innovative activity management - predetermines the use of the expert method itself. That is, finding out the opinions of experts on the impact of individual factors allows us to form a more objective view of their weight in the overall assessment, despite the obvious disadvantages of this method. At the first stage of assessment of the state of human resource innovative activity management based on the use of ratings, the weight of individual areas in the integrated assessment of the state of human resource innovative activity management is evaluated. To this end, experts are offered to distribute 10 weight points between three areas: human resources; conditions that ensure the innovative activity of human resources and the economic efficiency of the enterprise. After obtaining the necessary statistical material, it is possible to calculate how much important this or that direction of assessment is by averaging experts' opinions. At the second stage, there is a distribution of weight points throughout the selected directions by the blocks of assessment. Each direction of assessment involves obtaining quantitative information on the specific weight of several internal blocks of factors. Experts are offered to distribute 10 weight factors by each direction of assessment between the component blocks of its factors. The third stage of the assessment is to assign a weight factor to the individual factors within each block. The assessment procedure remains the same as in the previous case, as 10 weight points should be allocated among the factors selected within each block of factors.

Based on the data of the first three stages, it is recommended to draw a picture of the port's ideal human resource innovative activity management. Taking into account the maximum of 100 points corresponding to such a port, it is possible to calculate the maximum number of 
points that one or another human resources management factors could be estimated by.

The final, fourth stage is a factorial assessment of the state of management of human resources innovative activity in the given port, taking into account the maximum value of 10 points. It seems appropriate to highlight the five degrees of intensity of manifestation of the factor: missing; missing, but scheduled for introduction; present, but the cancellation is planned; present, but only formally; present. As can be seen from the table, the manifestation of different factors may have opposite orientation due to the fact that some factors are positive and others are negative.

Although no procedure for assessing the state of human resource innovative activity management can be $100 \%$ scientifically substantiated, we believe that the proposed method allows the most objective comparison of the ports based on the human resources innovative activity management practices established in each of them. The methodology is based on the assignment of weight points to the factors, and accordingly, the more points the port gains, the higher the level of human resource innovative activity management is. At the same time, the ports that received more than 75 points have a high level of human resource innovative activity management, while the ports with less than 25 points are considered as having unsatisfactory level of human resources innovative activity management.

\section{ASSESSMENT OF HUMAN RESOURCES OF THE SEA PORTS OF THE AZOV-BLACK SEA BASIN}

In general, in our opinion, it is possible to distinguish four groups of ports according to a possible assessment of the state of management of human resources innovative activity. The groups are presented in "Tabl 1"

TABLE I. RATING GROUPS OF PORTS, DEPENDING ON THE STATE OF HUMAN RESOURCE INNOVATIVE ACTIVITY MANAGEMENT

\begin{tabular}{|c|c|c|}
\hline $\begin{array}{c}\text { Number of } \\
\text { points }\end{array}$ & $\begin{array}{c}\text { Rating } \\
\text { group }\end{array}$ & $\begin{array}{c}\text { Characteristic of the state of } \\
\text { the management }\end{array}$ \\
\hline$>75$ & A & High \\
\hline $51-75$ & Б & Middle \\
\hline $26-50$ & B & Low \\
\hline$<25$ & $\Gamma$ & Unsatisfactory \\
\hline
\end{tabular}

Thus, the ranking of factors by the degree of influence on the state of management of human resources innovative activity and assessment of its status in specific ports was carried out by an expert group consisting of representatives of 17 commercial ports of the Black Sea-Azov basin. Based on the experts' opinions, the maximum number of points for each element of the assessment was determined. Also, for each element there following was determined: the weight of the factor (maximum possible value) and the indicator characterizing the situation in this port by the selected element of the assessment for 2016 and 2017. Based on the data obtained in this way the classification of the studied commercial sea ports by rating groups is presented in "Tabl $2 "$. As can be seen from the figure, the enterprise data is shown in the form of a histogram, each column of which corresponds to the value of the rating obtained by a separate sea port. As we can see, no port is included either in the worst or in the best group.

Thus, the generalization of information on the intensity of manifestation of all factors that determine the innovative activity of human resources has become the basis for a further overall assessment of the management process under study at the sea commercial ports.

TABLE II. CLASSIFICATION OF THE SEA PORTS OF THE BLACK SEAAZOV BASIN BY RATING GROUPS

\begin{tabular}{|l|c|c|}
\hline \multirow{2}{*}{\multicolumn{1}{|c|}{ Port }} & \multicolumn{2}{c|}{ Rating group } \\
\cline { 2 - 3 } & 2016 & 2017 \\
\hline The sea port of Batumi & B & B \\
\hline The sea port of Chernomorsk & B & B \\
\hline The sea port of Ismail & B & B \\
\hline The sea port of Rostov & B & B \\
\hline The sea port of Eregli (Erdemir) & B & B \\
\hline The sea port "Yuzhny" & B & B \\
\hline The sea port of Zonguldak & B & B \\
\hline The sea port of Novorossiysk & B & Б \\
\hline The sea port of Odessa & B & B \\
\hline The sea port of Poti & B & B \\
\hline The sea port of Mykolaiv & B & B \\
\hline The sea port of Kavkaz & B & B \\
\hline The sea port of Constanta & B & B \\
\hline The sea port of Tuapse & B & B \\
\hline The sea port of Varna & B & B \\
\hline The sea port of Kerch & B & B \\
\hline The sea port of Mariupol & B & B \\
\hline
\end{tabular}

Seaports: Yuzhny, Novorossiysk seaport, Odessa seaport, Constanta seaport during 2016-2017 were among the group with the average level of management of human resources innovative activity [3], [13]. The assessment makes it possible to compare the actual state of each of the factors that determine the level of management of human resources innovation activity at the enterprise with the optimal one and to get an idea of deviation from the best indicators both at the level of the general state of management of human resources innovative activity and at the level of individual factors. The frequency of distribution of enterprises by rating groups is given in "Tabl 3".

TABLE III. FREQUENCY OF ALLOCATION OF PORTS BY RATING GROUPS

\begin{tabular}{|c|c|c|c|c|}
\hline \multirow{2}{*}{ Group } & \multicolumn{2}{|c|}{$\begin{array}{c}\text { Number of } \\
\text { ports }\end{array}$} & \multicolumn{2}{c|}{$\begin{array}{c}\text { Share of ports of the given } \\
\text { group, \% }\end{array}$} \\
\cline { 2 - 5 } & $\mathbf{2 0 1 6}$ & $\mathbf{2 0 1 7}$ & $\mathbf{2 0 1 6}$ & $\mathbf{2 0 1 7}$ \\
\hline A & 0 & 0 & 0,00 & 0,00 \\
\hline Б & 4 & 5 & 18,00 & 23,00 \\
\hline B & 13 & 12 & 82,00 & 77,00 \\
\hline$\Gamma$ & 0 & 0 & 0,00 & 0,00 \\
\hline Total & 17 & 17 & 100,00 & 100,00 \\
\hline
\end{tabular}

The conducted assessment of the management of human resources innovation activity on the basis of ratings has allowed determining its general status in the seaports of the Black Sea-Azov basin, paying attention to the leaders. But such an analysis would not be sufficient for executives to determine the direction of corrective actions and the further improvement of the human resource management system in accordance with the requirements of exterior environment. The formed information base gives the opportunity to carry out deeper assessment in certain specific areas which characterize the state of management of human resources innovative activity by a number of aspects. That is, information concerning the level of intensity of manifestation of all factors that determine the state of management of human resources innovative activity makes it possible to 
determine a number of specific sub-rating indicators. Such indicators are often used in statistics when conducting rating assessment.

It is considered appropriate to calculate a certain system of such indicators, which include: the state of human resources; conditions of innovative activity; economic efficiency of management; the impact of labor humanization on human capital; the impact of labor life quality on intellectual capital; the impact of corporate values on organizational capital; the impact of the socio-psychological climate on social capital; the impact of motivation and quality of life on the innovation and investment opportunities of the port.

The first sub-rating under study (1) is the state of human resources. This sub-rating reflects the state of development of human resources components. Information on the level of this sub-rating enables managers to determine which of the indicators that characterize them in each unit require close attention and development. In addition, there is an opportunity to compare the results of the assessment of these factors with the best practices for managing human resource innovative activity. Sub-rating of conditions that ensure the realization of innovative activity of human resources (2). Information on the level of this indicator gives an idea of the level of realization of conditions that ensure the implementation and functioning of innovative activity of human resources, i.e., the actual practice of management, "Corporate Values", "Humanization of Labor", "Social and psychological climate", "Stimuli and motivation", "Quality of Labor Life" and how they meet the declared standards and best practices for managing the human resources innovative activity. Sub-rating of the conditions that ensure the realization of the human resources innovative activity and the state of human resources in various aspects create the basis for obtaining a high evaluation of the next sub-rating economic efficiency. Sub-rating of economic efficiency of the sea port management (3). This indicator makes it possible to determine the level of efficiency of the management of the seaport and to compare it separately at different enterprises. Both for managers and regional and state authorities, which focus primarily on economic efficiency, this indicator is a signal for making appropriate decisions on the development and support of the enterprise under study. Next, let's look at more interesting information for the head of the sea port that takes into account the actions of several specifically selected factors. This allows you to see "bottlenecks" in the enterprise and see similar situations in other sea ports of other countries. Sub-rating the impact of humanization of labor on human capital (4). The influence of such a component of the conditions of activation of innovative activity as "humanization of labor" on "human capital" is very important in the study, because it gives an opportunity to judge both the current state and prospects in the field of human resources management. The high value of the subrating of the impact of humanization of labor on human capital may be a signal of the feasibility of maintaining and developing the enterprise, even at low values of other subratings, because in this case it is possible to speak about the existence of a high possibility of growth of these indicators in the future due to the measures that are being taken and will be taken by the management of a particular sea port.
Sub-rating the impact of quality of labor life on intellectual capital (5). This sub-rating is based on a set of indicators that characterize the quality of labor life and intellectual capital, the degree of management's orientation to the future, the development of a sea port in the long run. A manager who focuses on the innovative development of the enterprise and does not count on the immediate results from the efforts made in this process, such an indicator is a signal for making a positive management decision, because for human resources aimed at innovation, high quality of labor life is extremely important. Sub-rating the impact of corporate values on organizational capital (6). This subrating is an indicator that can be used primarily to determine how the enterprise organizational culture affects organizational capital, that is, the rules and procedures, rules and regulations of an enterprise activity. Provided that most employees share the rules and standards of the organizational culture of the enterprise, this indicator is an important signal of the organizational culture compliance with the needs of the enterprise and vice versa. Sub-rating the impact of sociopsychological climate on social capital (7). This indicator combines the manifestation of the factors that characterize the state of the socio-psychological climate and the component of social capital. The value of this sub-rating is important both for the employees of the enterprise and for its managers, who will receive with its help the information on compliance of ethical norms of the enterprise, culture of relations, psychological compatibility with the needs of human resources in the field of information exchange, existence of informal groups among the employees and so on. Sub-rating the impact of motivation and quality of life on the innovation and investment opportunities of the seaport (8). This sub-rating characterizes the interrelation of several groups of factors: "stimuli and motivation" and "quality of labor life" and "port innovation potential" and its "investment opportunities". Therefore, its value is of utmost importance to employees, whose activities are focused on innovation, as they evaluate the compliance of these components with their needs, as well as the management of the enterprise to identify opportunities for innovative development. Comparison of enterprises by this indicator makes it possible to identify those that are most close to the main goal of managing the human resources innovative activity of the sea ports. Information on the state of management of innovative activity of human resources of sea ports at the surveyed enterprises by sub-rating indicators is summarized in the form of "Tabl 4", which shows the values calculated for each sub-rating by the above method. The calculations of sub-rating indicators are the basis for the analysis and give the opportunity to form a detailed idea of both the general state of management of human resources innovative activity at the enterprise and the state of specific areas of assessment. Such analysis can be the basis for comparing the actual level of the enterprise with the ideal indicators and indicators of enterprises that are evaluated according to the above methodology. Thus, as the results of the rating assessment show, the level of management of human resources innovative activity at the studied leading sea ports of the Black Sea-Azov basin remains low. Most of the surveyed enterprises can be assigned to the group B of the rating status of management of human resources innovative activity. This fact confirms the necessity for improving the system of management of human resources 
innovative activity at the sea ports, at the same time the described technique allows to define precise directions of such improvement, in other words, it gives the management of the sea ports the tool of improvement of a state of management of human resources innovative activity. The results of the assessment of the state of management of human resources innovation activity are a tool of managerial influence. Another useful aspect of this is the ability to obtain information about clustering of ports regarding the closeness of their values to the overall average in the group. This management tool gives the manager additional information about the actions of colleagues and competitors, as well as determines the actions of similar factors of exterior environment that equally affect the ports in one group.

Thus, the assignment of an enterprise to a particular group as a result of the assessment of the port management innovative activity of human resources on the basis of the rating approach and establishment of specific sub-ratings, cluster analysis by groups becomes a basis for the port managers, investors, consumers, regional and state authorities in making decisions at different levels. But for practical application and spreading, a mechanism is needed that will make effective use of this toolkit. Such a mechanism may be a decision-making procedure that will determine the place of such an assessment in the port's human resource innovative activity management system.

\section{CONCLUSIONS}

Based on the research of the concept of human resource innovative activity management, approaches to their realization and de-termination of the range of factors that determine its condition, the necessity of a comprehensive assessment of the state of human resource innovative activity management through the use of rating methodology is substantiated. Using such an assessment will allow the manager to obtain an integrated, comprehensive assessment of the situation at the enterprise, as well as to compare it with the industry, to identify their competitors.

It is established that the procedure of rating assessment of the state of human resource innovative activity management has a certain purpose, structure of directions and is carried out at several stages. Summarizing of the results of the assessment of the management status by the proposed structural blocks of factors, has allowed us to obtain an integrated rating indicator for the sea port and a number of specific rating indicators, the values of which are used to establish a rating group of the sea commercial ports. In accordance with the results of the assessment of the management status and the possibility of their further interpretation, the scale for allocation of rating groups of ports is proposed. It is proved that the application of such assessment allows comparing the actual state by each of the factors, which determines the level of management of human resources innovative activity with the optimal one for the industry and calculating the deviation. It is proposed to supplement the rating of the state of human resources management by graphically presenting the results of the analysis in the form of constructing a profile of the situation of the state of management of human resources innovative activity of the studied sea port.

The established information base on the state of human resources management makes it possible to identify a number of specific sub-rating indicators. An approach is proposed to identify the areas of analysis of the status of management of innovative activity of sea ports based on the use of such indicators as: composition of human resources, conditions for innovative activity, economic efficiency of management and indicators of impact: humanization of labor on human capital; quality of labor life on intellectual capital; corporate values on organizational capital; social and psychological climate on social capital; motivation and quality of life for the port's innovation and investment capabilities, which will provide a basis for developing recommendations and immediate response to improve the quality of human resource innovative activity management.

Based on the use of cluster and variance analysis, the sea ports have been grouped according to the closeness of their values to the overall average value in the group. Such a management tool gives the manager additional information about the possibility of deter-mining the impact of similar factors of the exterior environment on the enterprises of one group and becomes the basis for making management decisions at different levels.

\section{REFERENCES}

[1] L. Nikolaieva, "Development of Ukrainian ports: organizational and investment support", Bulletin of the Azov State Technical University. Series: Economic Sciences, Vol. 34, pp. 245-251, 2017. [in Ukrain].

[2] L. Nikolaieva, Improvement of organizational and economic mechanism of management of development of enterprises of the maritime industry, Odessa: OMA, 2017. [in Ukrain].

[3] The official site of the Novorossiysk Seaport, 2017. [Online]. Available: http://www.nmtp.info. Accessed on: April 15, 2017.

[4] Official Website of the Administration of Seaports of Ukraine, 2017. [Online]. Available: http://www.uspa.gov.ua/en. Accessed on: April $17,2017$.

[5] Official site of Rostov Port Joint Stock Company, 2017. [Online]. Available: http://rostovport.ru. Accessed on: April 15, 2017.

[6] The official site of the Kerch Commercial Port, 2017. [Online]. Available: https://crimeaports.ru/filialy/kerchenskij-torgovyj-port Accessed on: April 18, 2017.

[7] The official site of the Caucasus seaport, 2017. [Online]. Available: http://kavkaz.azovseaports.ru. Accessed on: April 21, 2017.

[8] The official website of the Seaport, 2017. [Online]. Available: http://www.potiseaport.com. Accessed on: April 15, 2017.

[9] The official site of Varna seaport, 2017. [Online]. Available: http://www.port-varna.bg. Accessed on: May 15, 2017.

[10] The official website of the Eregli Port, 2017. [Online]. Available: https://www.shippingexplorer.net/en/port/karadeniz-eregli. Accessed on: May 12, 2017.

[11] The official site of Batumi Port, 2017. [Online]. Available: https://www.batumiport.com. Accessed on: April 28, 2017.

[12] Official Website of Zonguldak Port, 2017. [Online]. Available: https://www.searates.com/port/zonguldak_tr.htm. Accessed on: April 14, 2017.

[13] Official Website of the Tuapse Maritime Commercial Port, 2017. [Online]. Available: http://www.tmtp.ru. Accessed on: May 12, 2017 